\title{
An Investigation into Domestic Energy Consumption Behaviour and Public Awareness of Renewable Energy in Qatar
}

\author{
Wadha Al-Marri ${ }^{1}$, Amin Al-Habaibeh ${ }^{1}$ and Matthew Watkins ${ }^{2}$ \\ ${ }^{1}$ Innovative and Sustainable Built Environment Technologies Research Group (iSBET), \\ School of Architecture, Design and the Built Environment, Nottingham Trent University, UK \\ ${ }^{2}$ Sustainable Consumption Research Group, School of Architecture, Design and the Built \\ Environment, Nottingham Trent University, UK
}

\begin{abstract}
Governments around the world are trying to find viable solutions for reducing carbon emissions and pollution, one of the primary sources of which is domestic household consumption. Although Qatar is rich in fossil fuel energy resources, there is a strategic drive towards sustainability to decrease energy consumption overall whilst increasing the nation's dependence on clean and renewable energy. One of the areas to enhance sustainability is through reducing and managing the energy demands and habits of domestic users. This research examines the current energy use in Qatar with a view to making recommendations in regard to challenging and improving consumer behaviour in respect to energy efficiency. A mixed methods approach was untaken consisting of both qualitative and quantitative data. Quantitative data was gathered from a wide spread survey of $n=410$ Qatari based consumers in regard to their energy consumption behaviour, investigating avenues for enabling sustainable behaviour change. The qualitative data was been collected by interviewing a panel of energy experts in Qatar. The purpose of this research study is to gain valuable insight into Qatari resident's energy consumption behaviour and perception of renewable energy and sustainability. The results will help to identify solutions to Qatar's high consumption of electricity per capita. This study has further implications amongst similar nations and states to address energy consumptions where there is a natural abundance of fossil fuel energy resources. This study has found that user's education and awareness of the environmental impact is dependent on efficient energy monitoring and usage. However, due to the presence of energy subsidies in Qatar, citizens are not inclined to modify their energy consumption behaviour through economic means. This suggests that a greater awareness of the effects of excessive energy use is required through sustainability education to motivate behaviour change. The results of this study were analysed using self-determination and hierarchal needs theories, indicating that education and public engagement and awareness are the best options for domestic energy conservation in Qatar.
\end{abstract}

\section{Introduction}

Regardless of the energy source, all energy consumption comes with an environmental cost, whether through related emissions from burning fossil fuels or the extraction of materials for the manufacture of renewable sources and distribution networks. Coupled with this the use of electrical equipment in commerce, industrial and domestic environments has increased exponentially over the past 30 years [1]. Residential energy consumption has an important role to play in the entire energy consumption outcomes and it is closely linked with behavioural theories [2]. Gram-Hanssen [3] describes how and why residential energy

${ }^{*}$ Corresponding author. Tel.: +44 (0) 115848 2564. E-mail address: Amin.Al-Habaibeh@ntu.ac.uk 
consumption has always had a significant influence on the totality of energy consumption. According to Gram-Hanssen, this commenced with the introduction of electricity into homes, which initially was lonely concerned with lighting. However, the 1960's saw the introduction of labour saving devices in the home, with it a vast array electrically powered home appliances and tools. This practice has continued with a proliferation of such appliances consuming increasing amounts energy, in particular in the Middle East context a high-energy demands also comes from air-conditioning. In Europe there has been a drive to promote the adoption of energy efficient appliances driven by the EU energy consumption labelling directives first introduced in 1992, but also an increased awareness of the household energy costs to the consumer. In Qatar, such factors are not applicable as there is limited concern in relation to the cost of energy due to the relative low cost of energy in comparison to other EU countries $[4,5]$. However as the literature notes beyond a strive for energy efficiency there is a need to influence the consumers' energy consumption behaviour $[6,2]$. Because the energy efficiency benefits of products over the past 30 years has been diminished by an increase in the number of products owned and used in the same period [6]. While residential energy consumers have acquired greater knowledge of the need to conserve energy and to change energy consumption behaviour, many household energy consumers have not learned to conserve energy [7]. Therefore a combined approach of product efficiency and user behaviour change is required [6].

Whilst there has been a wealth of such research concerning user energy behaviour which seeks to understand and explaining domestic consumption behaviours and interventions for curbing energy usage habits and trends in Europe and the US [8]. Very little attention is paid to the domestic energy consumption in oil rich countries, particularly in the Middle East GCC countries, which have a very different culture both in regard to the energy affordability but also climatic conditions.

The theory of self-determination [2,9] can offer insights into how domestic energy users can be encouraged to conserve energy and embrace sustainable consumption habits. According to self-determination theory, individuals are either intrinsically or extrinsically motivated to behave in specific ways [10]. Intrinsic motivation occurs when an individual wants to perform a certain act for the reward or benefit associated with the act [10]. Extrinsic motivation refers to the desire to carry out a specific act for the sake of an external reward or penalty $[11,12]$. Thus, extrinsic motivation within the parameters of self-determination theory might explain why most governments seek to modify energy consumption behaviour through the use of economic persuasion [2].

Maslow's hierarchal theory of needs may explain the high domestic energy consumption habits, despite a prevailing knowledge of its harmful impact on the environment. According to Maslow's hierarchal theory of needs, individuals typically commit to their needs on a priority basis [12]. Thus, individual consumers arguably prioritise their needs for energy based upon their immediate physical environment, meaning that households are more likely to be fixated on comfort within the home, at a micro level rather than considering the global impact. As a result, there can be a conscious separation from the natural world and the difficulties and challenges associated with it. However, if a connection was established between the environmental impact and home comfort, individuals would be able to reflect upon how their actions could affect their long term lifestyle. Depriving future generations of opportunities to live such comfortable lives, making such connections can only occur when there is environmental, awareness and knowledge is present. 
Therefore, there is an urgent need to educate consumers on the importance of protecting the environment for sustaining their future needs, fulfilling their current needs without compromising the ability of future generations to fulfil their needs [13].

It is not sufficient to merely teach the public about the impact environmental deterioration, without also informing citizens of the steps they can take in reducing their energy consumption. In addition, the public also need to be assured that any conscious efforts made towards protecting the environment through energy conservation are going to make a difference strategically in the long term.

This research investigates energy consumption behaviour and attitudes towards renewable energy use in Qatar. Qatar is selected for this study because of, similar to the majority of energy rich countries, the difficulties arising from excessive household energy consumption [4,5]. Compounding the excessive domestic energy consumption in Qatar [5] is a reliance on desalination facilities to convert sea water into drinking water due to a shortage of suitable natural water sources [14]. Desalination facilities consume significant amounts of energy and the transporting of water to various end users is also energy intensive. Water is also in high demand due to the high temperatures in Qatar with household demand increasing [14]. Meeting this requirement for desalination requires high levels energy consumption which is an invisible and indirect additional source of domestic energy consumption. According to Environment and Energy Research Institute (QEERI), Qataris water consumption per day per person is one of the highest in the world [15]. When this is coupled with direct and visible household energy consumption, domestic energy consumption per capita in Qatar is considered excessively high when compared to other developed nations. In 2014 energy consumption reached $17 \mathrm{MWh}$ per capita with $35 \mathrm{~T}$ of carbon dioxide emissions per capita each year [16].

During the summer, domestic energy use increases due to the need for air-conditioning in response to the high temperatures [17] and potential ineffective building insulation. Energy consumption in Qatar per capita is the world's highest [5] and it is heavily subsidised for Qatari Citizens [4]. Therefore, the need for an improvement in energy efficiency and the reduction in energy demand is the most feasible solution to address global warming and climate change. Research into energy conservation in Qatar's households is very important for identifying means to reduce domestic energy consumption. Whilst investigating the feasibility of renewable energy adoption among Qatari residents. The challenge is to identify methods that can be employed to encourage and achieve energy efficiency amongst a population accustomed to high rates of energy consumption.

\section{Qatar: Background}

Qatar is one of the Gulf Cooperation Council (GCC) states, which are major global producers, growing significantly over the past fifty years [2]. Following a rise in oil and gas production in GCC states, consumption of energy, gas and water has increased exponentially [5]. Of particular concern is the increasing demand for electricity, particularly in the summer months when temperatures can exceed $40^{\circ} \mathrm{C}$, with GCC states' high electricity consumption and fossil fuel dependence having led to blackouts due to a lack in provision and infrastructure [18].

Qatar's economy is driven by its energy industry, its revenue from oil exports was US\$55 billion in 2012 and Qatar's oil and gas industry contributed about 57.8\% to Qatar's gross domestic product [19]. Qatar's economic growth and development combined with exponential population growth is of articular concern with regards to increasing energy 
consumption [20]. Water consumption is also a challenge to increasing energy consumption, with an average of 5 individuals per household in Qatar [21]. Each household consumes approximately 2,500 litres of water each day and Qatar has spent about $\$ 46,000$ per Qatari citizen on desalinated water and power production over the last decade [21]. The large household size in Qatar also attributes to large increasing energy consumption trends [19]. This is contrast to the US and Europe, where energy consumption has been declining since the 1970s due to public information and campaigns for renewable energy and energy conservation. Additionally, energy efficient household appliances have been increasingly adopted by American households [22]. A report issued by the Department for Business, Energy \& Industrial Strategy in the UK shows a decline in energy consumption from 2005 to 2016 [23].

Research in Ireland and Brazil has also indicated that an improvement in insulation and enhanced energy efficiency measures in buildings can contribute significantly in reducing energy consumption [24, 25]. The link between environmental knowledge and energy conservation was found to exist in a study conducted by Cotton et al [26]. The study found that, in general terms, simply directing and encouraging energy conservation behaviour is not sufficient to change consumption habits. Instead the key to changing energy consumption behaviour is through improved education so that consumers gain a full understanding of why energy conservation is imperative [26]. Pothitou, Hanna, and Hanna, conducted a study on the link between energy conservation and environmental knowledge, specifically considering domestic energy consumption [27]. This study found a positive correlation between environmental values, environmental knowledge and energy conservation [27]. A recent study in Austria has indicated that neglecting people's behaviour leads to a significant overestimation of potential energy savings due to building-standard improvement [28].

One of the main drivers of energy efficiency and adoption of renewable energy in US homes has been the high cost of electricity driven by oil prices [29]. However, this is not feasible in Qatar where electricity is provided to Qataris free of charge [30]. Furthermore with population growth and increased income for Qataris, the demand for electricity is expected to exceed capacity in the future if the rate of consumption continues [30]. It is therefore imperative that policy makers identify, implement and enforce domestic energy efficiency policies or an uptake in renewable energy. However, there are a number of challenges to overcome, such as motivating Qataris to buy into or adopt energy efficiency habits or renewable energy sources in their own homes. In order to address this pattern, it is necessary to gain insight into the Qatar residents' attitudes, perspectives and behaviour in relation to energy consumption and their amenability to renewable energy alternatives.

\section{Research Methodology}

An exploratory approach was taken within this study seeking to conduct "preliminary investigations into relatively unknown areas of research" [31]. The findings of which are descriptive in nature to effectively convey the perspectives and attitudes of Qataris into energy efficiency, energy consumption and renewable energy. An exploratory study was deemed suitable because the literature review revealed that research into energy behaviour within the GCC states is not a well explored phenomenon. This study used mixed methods through a quantitative wide reaching survey of Qatari domestic consumers and qualitative interviews with Qatari energy experts. Inclusion of these two groups permits data to be compiled from a broad perspective giving diverse insights into domestic energy consumption of energy and the potential for renewable energy solutions in Qatar. 
The results collected from Qatari residents allow for specific explanations in respect to their use and attitudes towards their energy consumption, their adaptability to energy efficiency measures and attitudes toward renewable energy. The interview scripts from the Qatari energy experts provide expert opinion into the attitudes of Qatari energy consumers, future energy efficiency measures and the realistic potential for the uptake in renewable energy.

A mixed methods study involves the collection of both qualitative and quantitative data [32, 33]. Qualitative data is typically small scale, narrative in nature and involves the collection of detailed and in-depth data [32]. Quantitative data on the other hand is large scale, numerical in nature and is capable of being reduced to statistical descriptions [32]. Quantitative data is typically collected from close-ended instruments such as surveys and questionnaires, permitting the collection of data that is capable of being calculated and measured [32].

\subsection{Consumer Survey}

For the purpose of this research study, the quantitative data was collected through the distribution of a survey among a population $n=410$ gathered through a convenience sampling technique. Convenience sampling is a technique whereby individuals are recruited accidentally or haphazardly [34]. In this regard, Qatar energy consumers were recruited on the basis of their availability and accessibility. However, data on the age distribution of respondents was collected and the following representations were found in the data. Respondents aged $18-24$ represented $31.6 \%$ of the returns, those aged $25-34$ represented the largest proportion of the sample $37.5 \%$, those aged $35-44$ represented $16.4 \%$ whilst $45-$ 54 years olds represented $11.5 \%$ and $55-64$ year olds $2.9 \%$ of the sample, there were no responses from over 65 year olds. Such an imbalance in the age ranges could be due in part to the way that the survey was promoted through social networks and conducted online and presents a weakness of a convenience sampling approach as no control over the sample is possible. Therefore, the results cannot be extrapolated across the population as a whole.

The survey was prepared in both Arabic and English and consisted of 3 sampling questions and 28 content questions which were a mixture of Likert Scale style questions and matrix and open ended questions. The questions were designed to be able to measure the responses from the consumers' in respect to their knowledge of energy consumption and conservation, and their attitudes towards renewable energy.

The Quantitative survey data was analysed using SPSS software and are reported statistically. A multiple regression analysis is conducted, which identifies and measures the relationship between "two or more independent variables" and explains its relationship to "variations in a dependent variables" [35].

\subsection{Expert Interviews}

Purposive sampling was used for the qualitative data to selection the energy experts interviewed. Purposive sampling is a technique by which individuals with the knowledge and information sought participate in the study [34]. Semi-structured interviews were conducted with a total of 11 energy experts in Qatar, comprising of energy policy representatives from a foundation, academics, petroleum companies and a private renewable energy company.

Semi-structured interview questions were used to permit the experts to give rich and detailed feedback on a series of designed to gather expert knowledge on the status of energy use in Qatar and the feasibility of renewable energy as a solution. All participants were recruited voluntarily and as such signed a consent form reflecting their informed knowledge of the study and their voluntary participation. 
The interviews were arranged and scheduled at the convenience of the participants. With the consent of the interviewees, the interviews were audio recorded. In order to improve the reliability of the interview data, the researcher took field notes during the interviews. The recordings were transcribed by the researcher after the interviews were conducted. To further enhance reliability and credibility, the interviews were conducted informally and were conversational in nature. This helped the interviewees to relax and to feel more open to discussing the interview questions.

To analyse the qualitative interview data a coding process was used for distinguishing commonalities, categories and discrepancies. In this regard "coding refers to the categorizing of observations into a limited number of categories" [36].

Data from all participants was collected anonymously to protect the participants' right to privacy and all were informed of the privacy measures in place to protect the data and their identities. Additionally, all the participants were informed of the nature of the research and of their right to withdraw from the study at any time. To further ensure that participation was voluntary, no monetary or cash alternative rewards were offered and no coercion tactics were used. To ensure the integrity of the data, the researcher created an audit trail so that the data was collected and documented as it was collected.

\section{Results and Discussion}

Out of the targeted 500 survey participants, 410 surveys were usable or completed correctly and returned. For a sample of $n=410$ for an infinity population this indicates a margin of error in the sampling process to be $\pm 5 \%$ with confidence interval of higher than $95 \%$. Confidence interval is the probability that the sample accurately reflects the attitude of the population while margin of error is the range in percentage that the population's response may deviate from the response of the sample. Overall $75.7 \%$ of the respondents were Qatari nationals and the remaining $24.3 \%$ were non-Qatari nationals, the only significance of this is the majority of the non-Qatari nationals were required to pay for their energy, with $18.5 \%$ of respondents paying for their energy vs $81.5 \%$ who didn't. This is an important consideration, because, the government's option for economic incentives in the form of penalties for modifying energy consumption behaviour is limited in Qatar. When examined under the theory of self-determination, consumers will likely be extrinsically motivated to conserve energy where they are committed to paying for energy usage. With a vast majority of the survey participants using electricity for free, the extrinsic motivation is not a satisfactory policy option.

As presented in Figure 1, the majority of the respondents switch off the lights when curtains are open. This demonstrated awareness of the need for enhancing sustainability by reducing electricity consumption. When answering the question about whether they left the lights on during the day whilst the curtains were open, $44.3 \%$ of respondents said they did sometimes, $47.4 \%$ said never and $8.31 \%$ said always. 


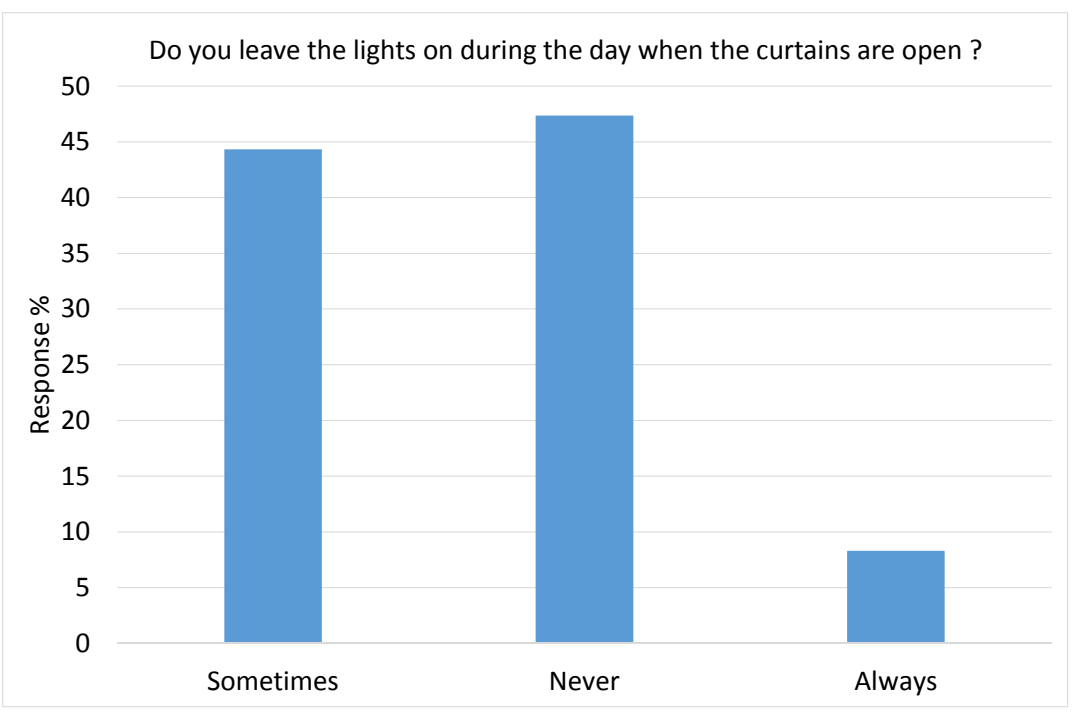

Figure 1: Leaving lights on during the day with the curtains open

Although a majority never engaged in the habit of leaving the lights on during the day with the curtains open, the majority is small with nearly as many participants sometimes leaving the lights on during the day with the curtains open. Meanwhile a very small number engaged in this practice all the time. Therefore, the link between knowledge and energy conservation is tenuous since, the respondents participating in the survey demonstrated knowledge of the environmental risk of energy consumption for the most part. Such mixed results are consistent with findings in a study conducted by Ajzen, Joyce, Sheikh and Cote, which found that knowledge of the environment had no influence on the behaviour of consumers in regards to conserving energy [37].

Even so, the results indicate that knowledge of the environment did have an impact on a $44.3 \%$ of the respondents' behaviour. Other studies in the literature have found a stronger correlation between environmental knowledge and consumption behaviour. This knowledge would generate hierarchal order needs and influence environmental values. According to hierarchal order theory, individuals behave in ways that reflect their prioritised needs. In this regard, where environmental knowledge exists, consumers are expected to understand their value of energy conservation for preserving their fundamental and basic needs through environmental protection.

The findings by Pothitou, et al., [25] and Cotton, et al., [26] are confirmed by some of the results of this study. For instance, the survey participants were asked if they opened a window to allow fresh air in the house while their air-conditioning systems are on, see Figure 2. A large majority $(69.19 \%)$ stated that they never engaged in this practice. Only $25.25 \%$ stated that they sometime opened a window to allow fresh air into the house while the airconditioning was on and $5.56 \%$ admitted to always doing this. The percentage of consumers engaging in this practice is quite small when one takes into account that a majority of the respondents do not pay for electricity. This could be a reflection of environmental values through knowledge as opposed to extrinsic motivation, but could alternately also indicate an understanding of the efficiency or the device. 


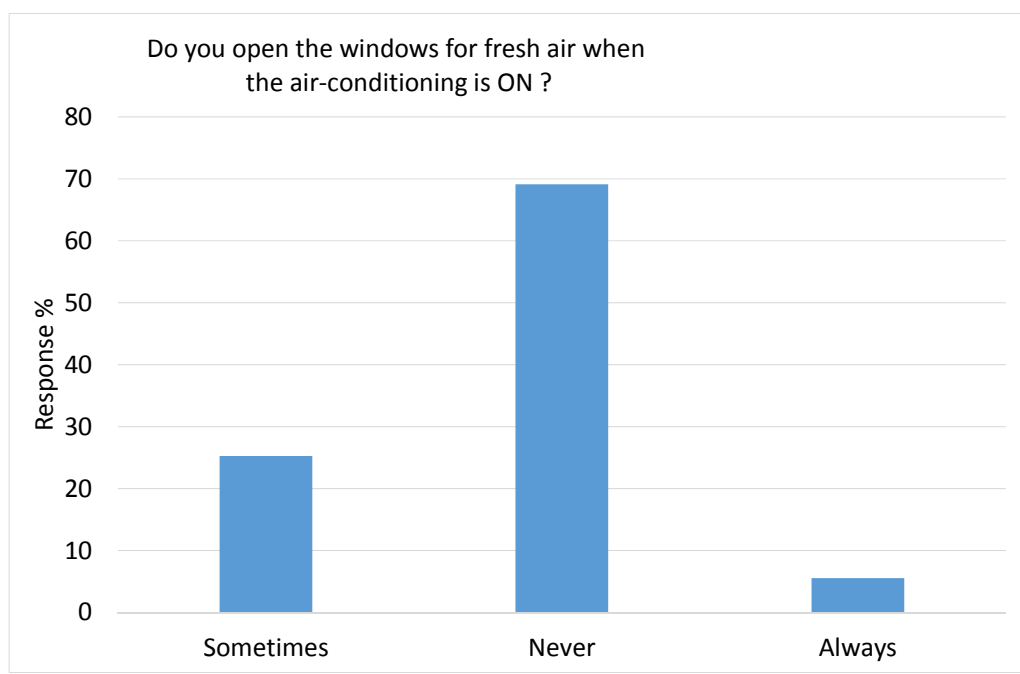

Figure 2: Open a window to allow fresh air in while the air-conditioning system is running.

It is therefore, hardly surprising that there were similar results for the question on whether or not participants turned off the lights if they were the last to leave the room, see Figure 3. Just over $60 \%$ of the participants said that they always turned off the lights if they were the last to leave a room. Just over $28 \%$ said that they engaged in this practice sometime and $11.25 \%$ admitted to never engaging in this practice.

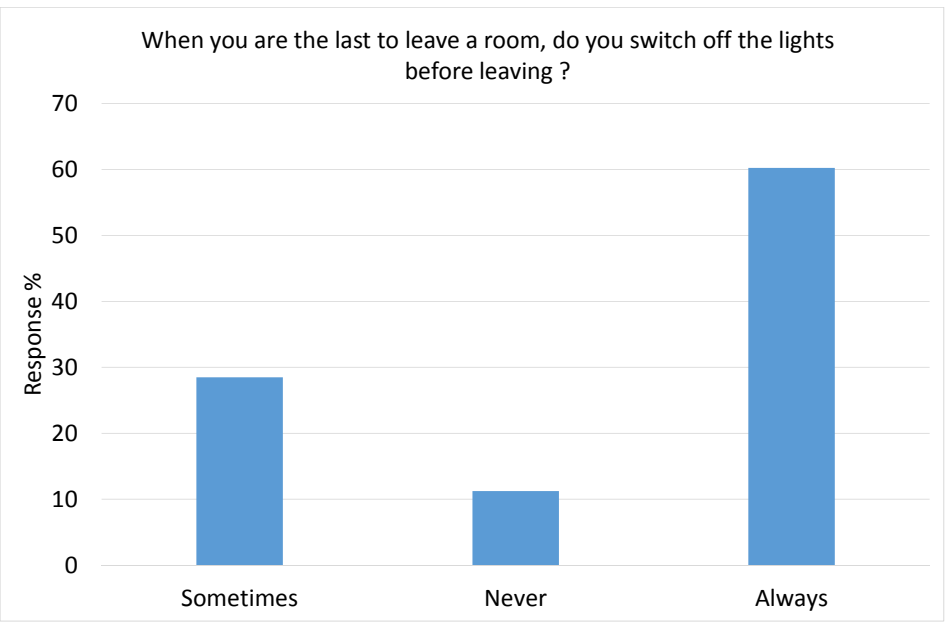

Figure 3: Turning off the Lights before leaving a room.

When asked about their consumption behaviour relative to the use of the personal computer or other electronic device, the results were varied, see Figure 4 . A slight majority $(41.85 \%)$ of the respondents said that they always turned off the power to the computer, television or other electronic device when not using it. Meanwhile, 35.34\% said that they only sometimes turned the power off to these items when not in use, compared to $22.81 \%$ who never did. However, these results are not alarming because electronic devices including televisions and personal computers have energy saving programmes which automatically put the device to sleep after a period of inactivity. However, more energy can be saved if the device is switched off ahead of the idle time. Therefore, specific knowledge on the environmental concerns and risks may improve environmental values and in turn, energy conservation habits. As Khan et al. point out, energy conservation is among policy-makers' "immediate and urgent social objectives" [38]. Therefore, it is important that policy-makers ensure that 
conservation knowledge includes knowledge of the environmental risks involved in excessive energy consumption.

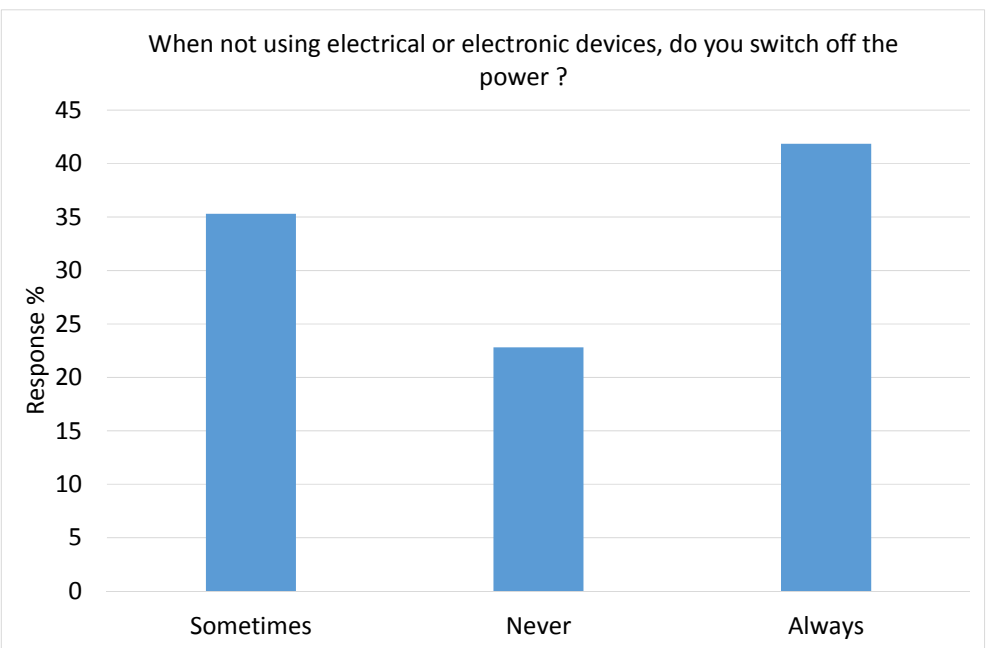

Figure 4: Turn the power off to electronic and electrical devices when not in use

As displayed in Figure 5, the use of energy efficiency measures such as programmable timers or controllers to manage energy use effectively among participants was mixed. While $56.28 \%$ of the respondents reported that they had an electricity controller or programmable timers in their home, $23.37 \%$ said they did not and $20.35 \%$ did not know if they did. Eleven respondents provided detailed open ended responses and the most common response from these was a lack of knowledge of what an electricity controller/programmable timer was or where one can be located.

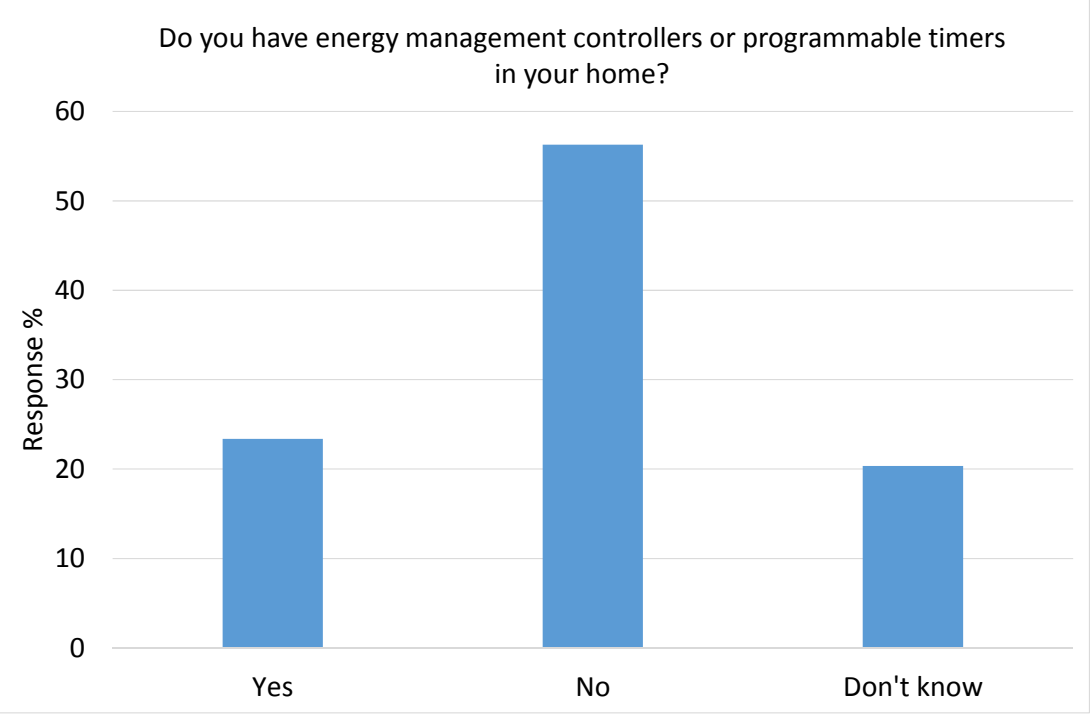

Figure 5: Energy efficiency measures using energy controllers/programme times at home.

Figure 6 shows that the results for a question on the use of energy efficient lightbulbs were quite different. Where $50.37 \%$ of the respondents said they did not use energy efficient lightbulbs, compared to only $32.42 \%$ who did and $17.12 \%$ who did not know. 


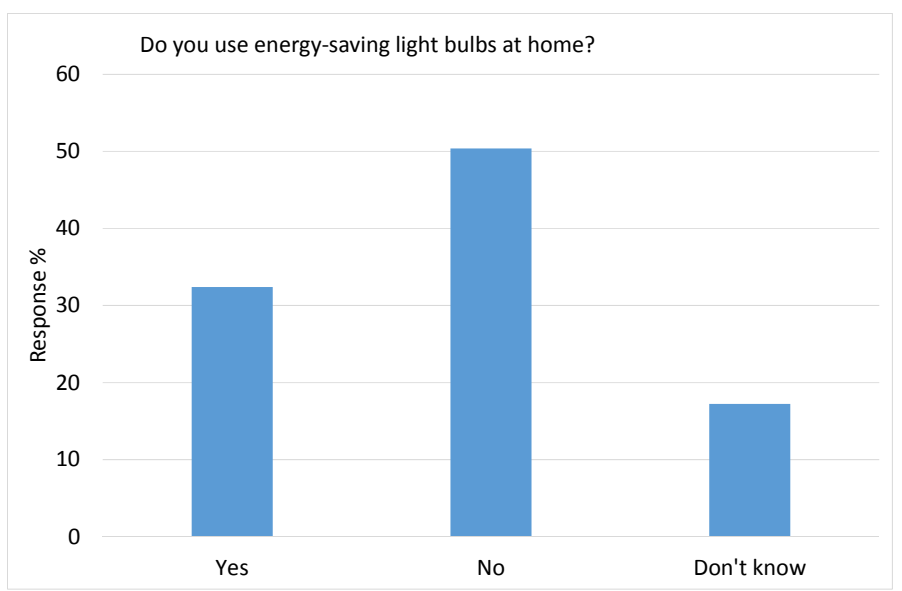

Figure 6: Use of energy efficient light bulbs

Another interesting observation, shown in Figure 7, was that $37.75 \%$ of the respondents said that their homes were insulated compared to $34.75 \%$ who said they were not and $26.50 \%$ who claimed they didn't know. Insulation is an important energy conservation tool since it reduces the heat transfer to the home and therefore reduces demand on the air-conditioning system.

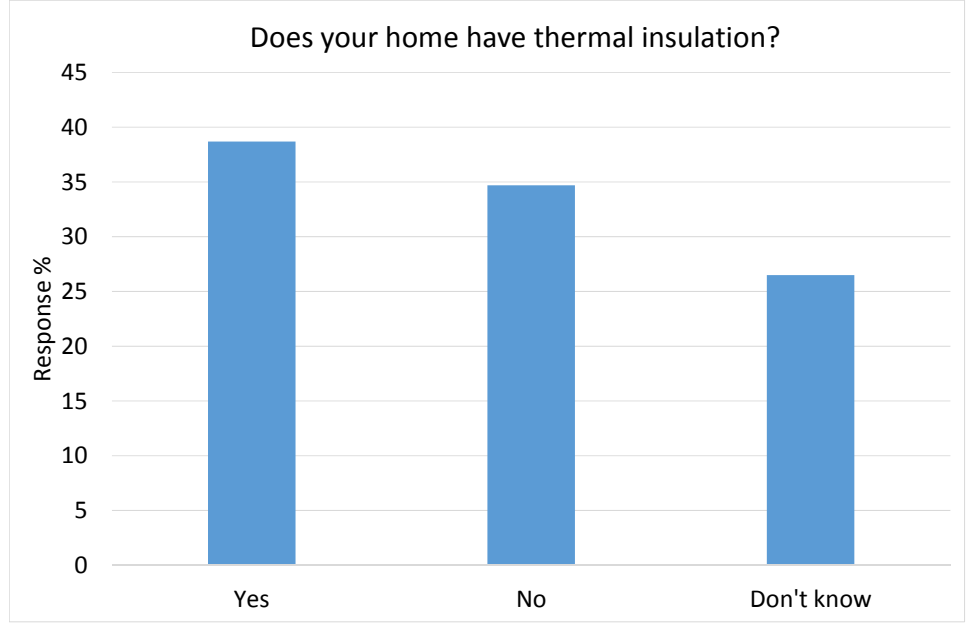

Figure 7: Availability of building thermal insulation

The study results also revealed that an overwhelming $71.75 \%$ of the respondents never checked to see how much electricity and gas they used, as shown in Figure 8. Only $17.50 \%$ did and $10.75 \%$ not aware if they checked or not. Such an answer is hardly surprising since the majority of the respondents do not have to pay for electricity. What was surprising however, is the fact that $83.42 \%$ of the respondents felt that energy should be saved, see Figure 9. 


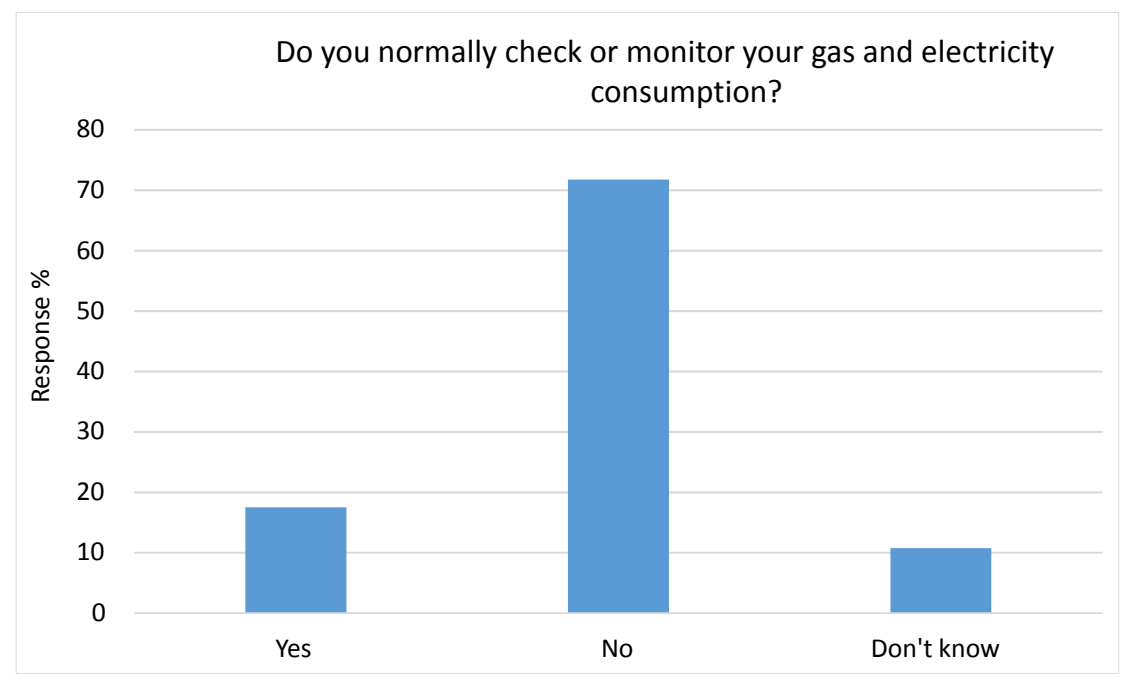

Figure 8: Monitoring of electricity and gas consumption

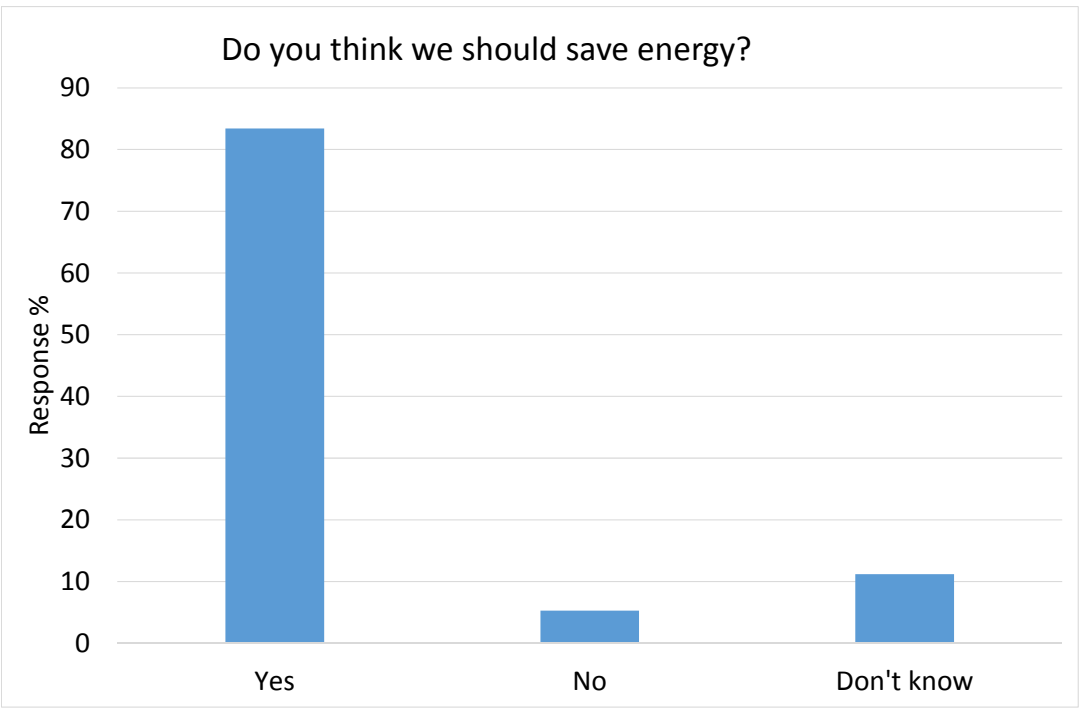

Figure 9: The need to save energy

These results concerning energy consumption habits and behaviour indicate an overwhelming support for saving energy, which is inconsistent with practice and habits. Overall, the results demonstrated a small majority in those that demonstrated energy saving behaviour despite their knowledge of environmental risks and awareness of the need to save energy. This suggests therefore that there is a lack of awareness of the link between energy use and practical actions amongst Qatari residents. Extrinsic motivations to address this are not currently a viable option due to the policies of energy subsidies that are in place and the fact the 81.55 of the respondents didn't pay for their energy usage. Therefore an option that encourages changed behaviour through intrinsic motivation needs to be explored. This may be achieved through environmental and energy education that creates and informs environmental values. According to hierarchal needs theory, when environmental values change, there will be a reordering of needs prioritising environmental safety and in turn energy conservation.

Figure 10, shows that when asked for their preferences in regards to renewable energy, $69.9 \%$ of the respondent's preferred solar energy. Only $3.3 \%$ selected wind, $0.8 \%$ chose wave and 
$1.8 \%$ chose biomass, but more than $20 \%$ did not know which renewable energy source they preferred. Solar energy is a practical and very feasible choice for Qataris due to the abundance of sunshine in the region [39]. In fact, the over-abundance of sunshine in the Middle East and North Africa convinced Mohammed et al. that the region can use solar energy and at the same time, supply it to Europe [40].

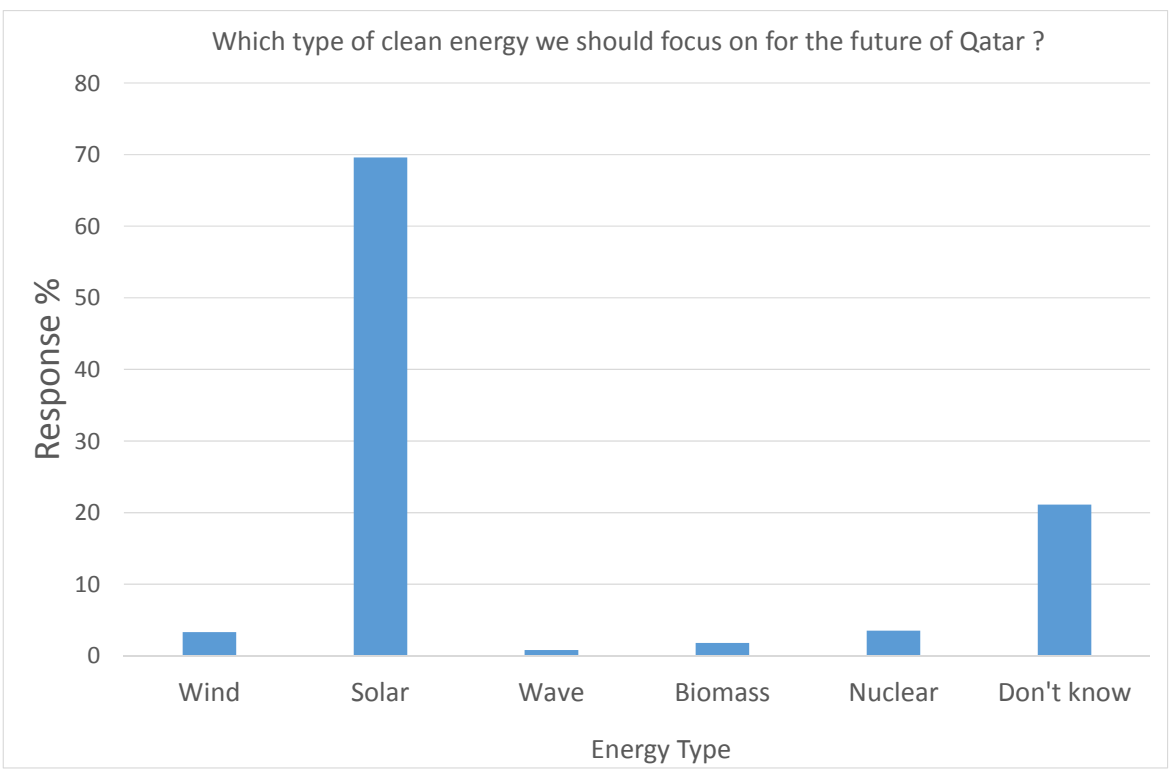

Figure 10: Renewable and low carbon energy preference

Figure 11, demonstrates the key influences that would encourage the respondents to adopt or use renewable energy. Out of 11 options presented, $50.5 \%$ of the respondents selected environmental responsibility as their main reason for using renewable energy. The second most popular option was patriotism and energy security $(32 \%)$, followed by cost $(28.7 \%)$, efficiency $(24.6 \%)$, reduction of electricity consumption $(22.8 \%)$, and societal reputation $(15.2 \%)$. Such results were surprising since the majority of the respondents admitted that the Qatari government's renewable energy policy was not clearly understood and did not have very unambiguous objectives. Furthermore $28.7 \%$ selected cost when only $18.5 \%$ pay for their energy.

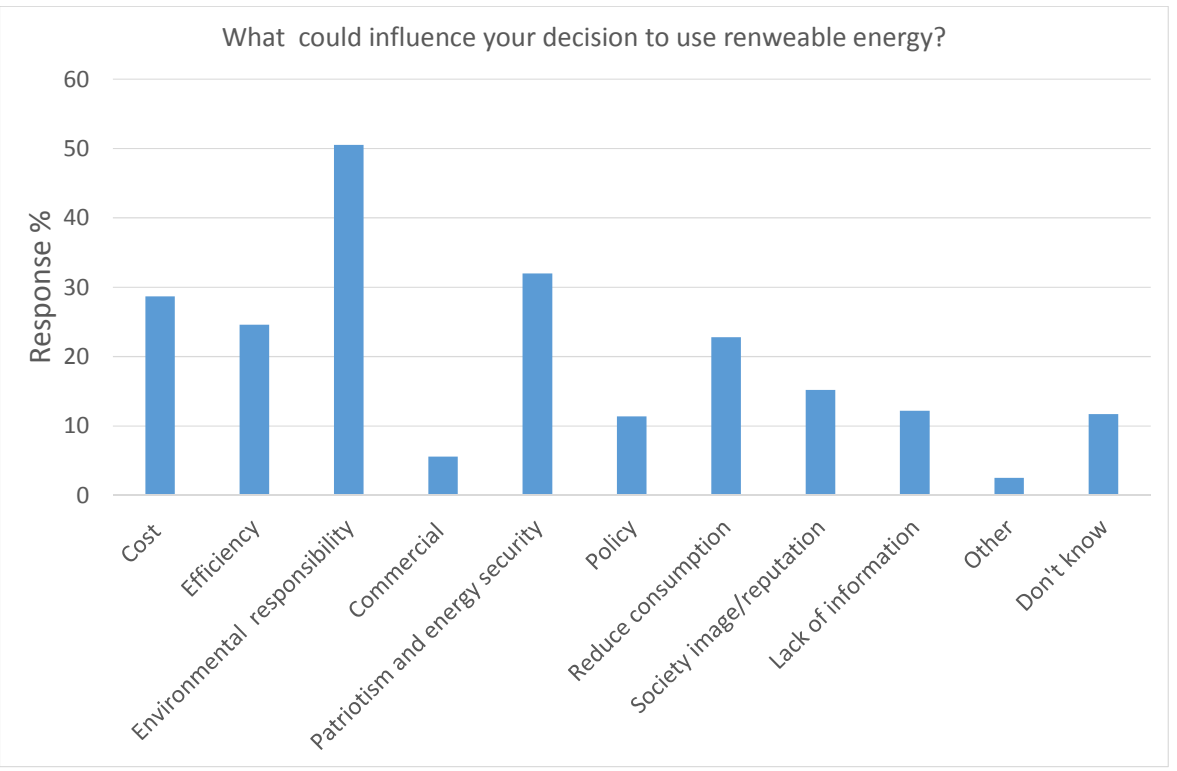




\section{Figure 11: Reasons for considering the use of renewable energy}

A vast majority of the respondents agreed that education positively impacted their awareness of renewable energy and practice of saving energy. Nearly $36 \%$ strongly agreed and $32.64 \%$ agreed, see Figure 12. Kandpal and Broman state that renewable energy is not easily understood by potential users and suppliers [41]. Therefore, education is important in establishing and promoting an increase in the use of renewable energy and should be a priority of all governments [41]. Khambalkar et al [42] conversely conducted a study which demonstrated that the global public in general had a good understanding of renewable energy. In this regard, the public knew that renewable energy was a clean option for energy consumption and as such, was a "good idea" [42].

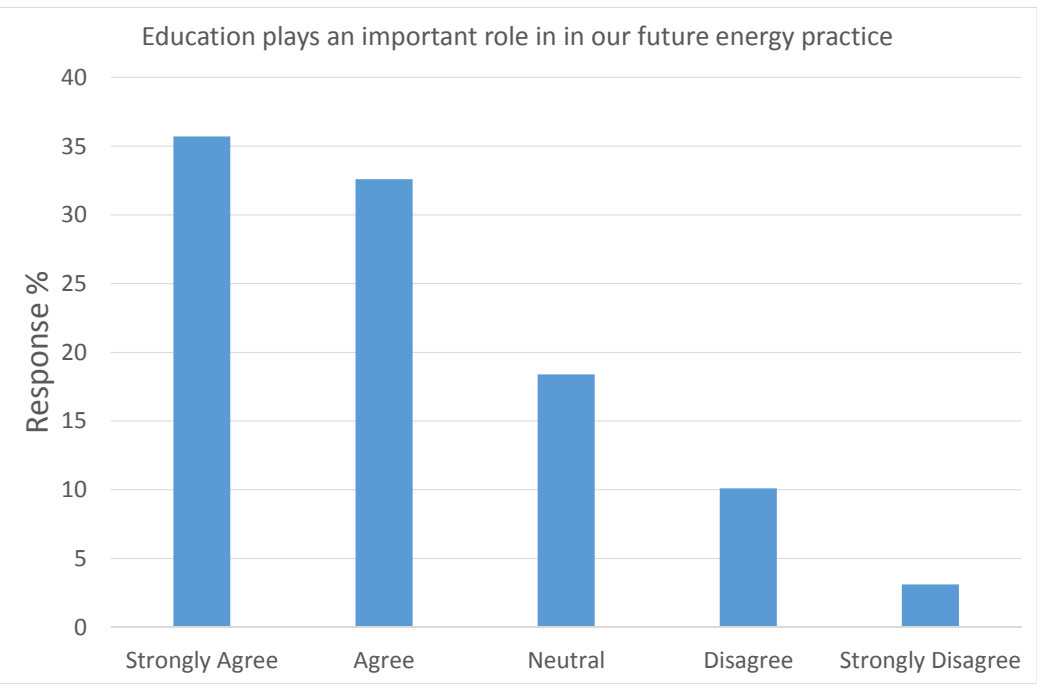

Figure 12: Role of education in increasing awareness of renewable energy and improvement in efficient energy practices.

The energy experts interviewed (Table 1), all agreed that solar energy was the preferred renewable energy option for Qatar. The experts thought that solar energy was a viable choice because of its availability and abundance of sunshine in Qatar. The interviewees however, generally agreed that completely transferring over to renewable energy was not a viable option. Instead it should be combined and gradually merged in with traditional energy sources. Moreover, it would be necessary to educate the public on the efficiency of renewable energy as they were of the opinion that renewable energy would not be promptly embraced by Qataris because they are generally unaware of its efficiency. 
Table 1: Interviewees' organisations and sectors

\begin{tabular}{|l|l|l|}
\hline Classification & Organisation & Number and Code of Interviewee \\
\hline \multirow{3}{*}{ Energy Policy Maker } & Qatar Foundation & $3: \mathrm{A} 1, \mathrm{~A} 2, \mathrm{~A} 3$ \\
\cline { 2 - 3 } & Qatar Petroleum & 2: B1, B2 \\
\cline { 2 - 3 } & Qatar Kahrama & 2: C1, C2 \\
\cline { 2 - 3 } & Qatar University & $2: \mathrm{D} 1, \mathrm{D} 2$ \\
\hline Private Companies & Alemadi Solar & 2: E1, E2 \\
\hline Total: 11 interviews
\end{tabular}

For the most part, the panel of experts that were interviewed did not feel that the Qatari government or its citizens were ready to embrace renewable energy. However, all 11 interviewees thought that renewable energy/solar in Qatar was possible, with 10 of the 11 interviewees stating that solar energy was possible anywhere in Qatar. One interviewee disagreed (B1) and suggested that the location was a deciding factor adding "Generally speaking, for solar power, the further you are from the sea the better. So central locations are preferred." Whilst also noting that weather data and micro climatic conditions also affect the efficiency. Central locations are more preferred because air near the sea is more corrosive, which could influence the reliability of the solar panels.

The panel of experts felt that both the government and the public needed to be more aware of the benefits of renewable energy. All 11 experts felt that the government's renewable energy policy was too broad to be understood, observed and enforced. One Interviewee (B2) stated that, the "government has to set priorities and manage expectations that there are more sustainable ways of living than the current way". With more research and development on renewable energy, the experts felt that the government could formulate a better and clearer renewable energy policy that Qataris can understand and comply with.

The panel of experts were particularly concerned that the Qatari citizens' access to free electricity has made them resistant to change. This was virtually a unanimous observation 10 of the panel shared. One interviewee's observation was representative of the panel's thoughts:

...the most prominent is the low cost of fossil fuels, which leads to lack of interest of institutions and individuals on renewable energy sources for the relatively high initial cost (E2).

One interviewee put it in far more simplistic terms "the attitude is simple: there is interest, but no incentives. If power is free, nobody will do anything” (B2). However, one expert stated "I think people now have sufficient awareness about renewable energy, as a clean source of energy and as sustainable energy as well." However, all interviewees felt that the public required more education on renewable energy in order to ensure wide spread adoption and acceptance.

One respondent made a more practical observation noting that:

...energy prices are subsidised in gulf countries and investing in renewable energy will not be profitable. There is no motivation to use renewable energy. For example, in Europe tax incentives are motivational but here we do not have taxes (A3). 
This indicates that perhaps diversification of the economy should come first because currently, there is no economic incentive for the transfer to renewable energy. Traditional oil based energy sources are a major economic asset for Qatar and a lack of incentives to motivate citizens to accept and use renewable energy.

It is therefore hardly surprising that $\mathrm{C} 1$ indicated that Qatar is not quite ready for conversion over to renewable energy when specifically stated:

Based on current technology economic circumstances renewable energy is necessary but we do not believe it will substitute the fossil based energy source at least until the end of this century, however it is considered to be a very important complement source of energy. It can meet the demand for remote areas, and as complement as mentioned above and for limited uses (C1).

Meanwhile, the lack of economic consequences has contributed to excessive energy consumption behaviour. This observation by the panel of experts is consistent with selfdetermination theory. In other words, without a penalty or economic incentive, Qatari citizens do not have the extrinsic motivation to modify their consumption behaviour. However, as discovered in the literature and discussed in this section, education on environmental risks and renewable energy can work to modify energy consumption habits and at the same time. Table 2 summarises the findings from the interviews.

Table 2: Summary of the findings from the interviews

\begin{tabular}{|l|l|}
\hline Limitations identified by the interviewees & Consequence or solution recommended \\
\hline Free or subsidised electricity & $\begin{array}{l}\text { No incentive to conserve energy or to seriously consider or } \\
\text { invest in renewable energy }\end{array}$ \\
\hline $\begin{array}{l}\text { Lack of public education and awareness of } \\
\text { renewable energy and need to conserve energy }\end{array}$ & $\begin{array}{l}\text { Government involvement in energy conservation and } \\
\text { environmental protection education needs to be enhanced } \\
\text { further. }\end{array}$ \\
\hline Broad energy policy & $\begin{array}{l}\text { Introduction of measurable objectives could lead to better } \\
\text { improvement in renewable energy utilisation. }\end{array}$ \\
\hline
\end{tabular}

\section{Conclusion}

This study confirms the findings in the literature suggesting that there is a correlation between energy consumption trends and education. The link was also found between renewable energy usage and environmental education. This information can be useful for policies makers within the government of Qatar when considering ways to implement and practice sustainable energy. Following the self-determination theory, once an individual is aware of the environmental risk associated with energy consumption, they are more likely to form environmental values and in doing so, will be likely conserve energy. Meanwhile, hierarchal needs theory suggests that a greater awareness will permit recognition of energy conservation and environment protection as higher order needs and therefore priorities.

The cost of electricity would ordinarily deter excessive energy consumption in households. However, this is not the case for Qatari residents since electricity is free for so many. Therefore, motivation through an economic penalty or punishment suggested by selfdetermination theory is therefore not currently applicable subject to policy change. Therefore, knowledge of energy conservation in homes, through education is of paramount importance. Education and information that improves Qataris awareness of the danger and risks to the environment and health of using fossil fuels would be likely to improve energy efficiency and shape the way forward for renewable energy adaptation within Qataris' homes. 
An awareness of the link between energy consumption and its resulting environmental impact would invoke the kind of thinking and action contemplated by Hierarchal Order Needs theory. Building an appreciation of the environmental damage, caused by excessive energy consumption and what this means for the future of subsequent generations, job security and lifestyles, would enable Qatari energy consumers to perceive energy conservation and environmental conservation as higher, fundamental needs. Adopting approaches such as those observed in the US and Europe, with a progressive public education and campaigns on residential energy conservation.

Replacing inefficient electrical appliances and establishing a higher standard of energy efficiency for new products can also be used to encourage domestic reduction in energy consumption. If is reasonable to assume that Qataris would adopt energy efficient household appliances where they are aware of their existence and benefits, without the economic benefit. If the government of Qatar takes this approach and implements this awareness in schools and public media, both current and future generations would more likely adopt and transfer residential energy conservation habits.

In recent years, Tarsheed, which is part of Qatar General Electricity \& Water Corporation (Kharamaa) has been "providing mechanisms for improving efficiency, ensuring sustainability, and incorporating best practices in project and program implementation" [43] including sustainability guidance for the citizens of Qatar [44] and specially children [45] to drive behavioural change. Also Qatar General Electricity \& Water Corporation (Kharamaa), the company that provides Qatar's need of electricity and water services, is working actively on sustainability themes [46]. Therefore, Qatari education and policy making seems to be moving forward into enhancing sustainability by increasing awareness and enhancing sustainability education.

\section{Acknowledgment}

The authors would like to thank the Cultural Attaché Office, Embassy of the State of Qatar in the UK for supporting this research work.

\section{References}

[1] Sadorsky, P. 2011. Trade and energy consumption in the Middle East. Energy Economics, 33(5), 739-749. https://doi.org/10.1016/j.eneco.2010.12.012.

[2] Al-Marri, W., Al-Habaibeh, A and Abdo, H. 2017. Exploring the Relationship between Energy Cost and People's Consumption Behaviour. Energy Procedia, 105, 3464-3470. http://doi.org/10.1016/i.egypro.2017.03.793.

[3] Gram-Hanssen, K. 2011 Understanding Change and Continuity in Residential Energy Consumption. Journal of Consumer Culture, 11(1), 61-78.

[4] Sdralevich, M.C.A., Sab, M.R., Zouhar, M.Y. and Albertin, G., 2014. Subsidy reform in the Middle East and North Africa: Recent progress and challenges ahead. International Monetary Fund.

[5] El-Kairi, L. and Husain, M. 2014. Prospects for Renewable Energy in GCC States: Opportunities and the Need for Reform. The Oxford Institute for Energy Studies, 1-25. 
[6] Gram-Hanssen, K., 2013. Efficient technologies or user behaviour, which is the more important when reducing households' energy consumption? Energy Efficiency, 6(3), pp.447-457.

[7] Burger, P. et al. 2015. Advances in understanding energy consumption behavior and the governance of its change-outline of an integrated framework. Frontiers in Energy Research, 3, p.29.

[8] Darby, S., 2006. The effectiveness of feedback on energy consumption. A Review for DEFRA of the Literature on Metering, Billing and direct Displays, 486(2006), p.26.

[9] Ryan, R. M., \& Deci, E. L. (2000). Self-determination theory and the facilitation of intrinsic motivation, social development, and well-being. American Psychologist, 55(1), 68-78. http://dx.doi.org/10.1037/0003-066X.55.1.68

[10] Frederiks, E.R., Stenner, K. and Hobman, E.V., 2015. Household energy use: Applying behavioural economics to understand consumer decision-making and behaviour. Renewable and Sustainable Energy Reviews, 41, pp.1385-1394.

[11] Maslow, A.H 1943. A Theory of Human Motivation. Psychological Review, 50(4), 370 $-396$.

[12] Wu, W. 2012. The relationship between incentives to learn and Maslow's hierarchy of needs. Physics Procedia, 24,1335-1342. https://doi.org/10.1016/i.phpro.2012.02.199.

[13] Brundtland, G.H., 1987. Report of the World Commission on environment and development:"Our Common Future". United Nations.

[14] Darwish, M. 2013. Towards Energy Conservation in Qatar. Open Journal of Energy Efficiency, 2, 176-191.

[15] Gulf Times, (2013), Daily per capita water usage in Qatar: 500 litres. Online: http://www.gulf-times.com/story/372827/Daily-per-capita-water-usage-in-Qatar-500litres

[16] International Energy Agency, online:

https://www.iea.org/statistics/statisticssearch/report/?country=Qatar\&product=indicator $\underline{\text { s }}$, accessed on 29 December 2017.

[17] US Energy Information Administration EIA. (2014). Qatar. Online: http:/www.europarl.europa.eu/meetdocs/2009 2014/documents/darp/dv/darp20140213 04_darp20140213_04_en.pdf (Retrieved 26 January 2017).

[18] El-Katiri, L and Fattouh, B. (2017) 'A Brief Political Economy of Energy Subsidies in the Middle East and North Africa' in G. Luciani (ed.) Combining Economic and Political Development : The Experience of MENA, International Development Policy series 7 (Geneva: Graduate Institute Publications, Boston: Brill-Nijhoff), pp. 58-87

[19] Ministry of Development Planning and Statistics in Qatar (2015). Analysis of the Results of Population, Housing and Establishments Census 2015. Online: https://www.mdps.gov.qa/en/statistics/Statistical\%20Releases/General/Census/Outcom e_Analysis_of_Census_of_Population_Housing_and_Establishments_2015 en.pdf ; Accessed on 20 December 2017.

[20] Williams, J., Bhanugopan, R. and Fish, A., 2011. Localization of human resources in the State of Qatar: Emerging issues and research agenda. Education, Business and Society: Contemporary Middle Eastern Issues, 4(3), pp.193-206. 
[21] HollandPlusYou. (2016). Opportunities for Dutch Business in the Gulf Region -Water, Online: https://www.netherlandsworldwide.nl/binaries/ennederlandwereldwijd/documents/publications/2017/02/03/opportunities-for-dutchbusinesses-in-the-gulf-region-water-sector-lo res.pdf/opportunities-for-dutchbusinesses-in-the-gulf-region-water-sector-lo res.pdf, Accessed on 20 Dec 2017.

[22] Gellings, C.W., Wikler, G. and Ghosh, D., 2006. Assessment of US electric end-use energy efficiency potential. The Electricity Journal, 19(9), pp.55-69. https://doi.org/10.1016/j.tej.2006.10.001.

[23] Walters, L. 2017. Energy Consumption in the UK. Department for Business, Energy \& Industry Strategy. Online: https://www.gov.uk/government/uploads/system/uploads/attachment data/file/573269/ ECUK November 2016.pdf Accessed January 2017.

[24] O’Doherty, J., Lyons, S. and Tol, R.S., 2008. Energy-using appliances and energysaving features: Determinants of ownership in Ireland. Applied Energy, 85(7), pp.650-662.

[25] Triana, M.A., Lamberts, R. and Sassi, P., 2018. Should we consider climate change for Brazilian social housing? Assessment of energy efficiency adaptation measures. Energy and Buildings, 158,(1) pp.1379-1392.

[26] Cotton, D., Miller, W., Winter, J., Bailey, I. and Sterling, S., 2016. Knowledge, agency and collective action as barriers to energy-saving behaviour. Local Environment, 21(7), pp.883-897.

[27] Pothitou, M., Hanna, R.F. and Chalvatzis, K.J., 2016. Environmental knowledge, proenvironmental behaviour and energy savings in households: An empirical study. Applied energy, 184, pp.1217-1229.

[28] Holzmann, A. and Schmid, E., 2018. Consumer behaviour in the residential heating sector in Austria: Findings from a bottom-up modelling approach. Energy and Buildings, 158, pp.486-493.

[29] Alberini, A., Gans, W., Velez-Lopez, D. 2011. Residential consumption of gas and electricity in the U.S: The role of prices and income. Energy Economics. 33 (5), pp. 870-881.

[30] Meier, A., Darwish, M. and Sabeeh, S., 2013. Complexities of saving energy in Qatar. In ECEEE Summer Study Proceedings (p. 43). Online: https://www.eceee.org/library/conference proceedings/eceee_Summer_Studies/2013/1foundations-of-future-energy-policy/complexities-of-saving-energy-in-qatar/

[31] Blanche, M.T., Blanche, M.J.T., Durrheim, K. and Painter, D. eds., 2006. Research in practice: Applied methods for the social sciences. Juta and Company Ltd.

[32] Tashakkori, A. and Teddlie, C. eds., 2010. Sage handbook of mixed methods in social \& behavioral research. SAGE Publications, Thousand Oaks, California. 
[33] Creswell, J.W. and Clark, V.L.P., 2017. Designing and conducting mixed methods research. SAGE Publications, Thousand Oaks, California.

[34] Som, R.K., 1995. Practical sampling techniques. CRC press, New York.

[35] Allen, P.J. and Bennett, K., 2007. SPSS for the health and behavioural sciences. Thomson Learning.

[36] Monette, D.R., Sullivan, T.J. and DeJong, C.R., 2013. Applied social research: A tool for the human services. Cengage Learning, pp429.

[37] Ajzen, I., Joyce, N., Sheikh, S. and Cote, N.G., 2011. Knowledge and the prediction of behavior: The role of information accuracy in the theory of planned behavior. Basic and applied social psychology, 33(2), pp.101-117.

[38] Khan, S., Abdo, H. and Al-Ghabban, A., 2015. Investigating consumer awareness of energy efficiency in Saudi Arabia. Energy Research Journal, 6(1), 1-6.

[39] Cen, Z., Kubiak, P., López, C.M. and Belharouak, I., 2017. Demonstration study of hybrid solar power generation/storage micro-grid system under Qatar climate conditions. Solar Energy Materials and Solar Cells, 180.

[40] Mohamed, A.M., Al-Habaibeh, A., Abdo, H. and Elabar, S., 2015. Towards exporting renewable energy from MENA region to Europe: An investigation into domestic energy use and householders' energy behaviour in Libya. Applied Energy, 146, pp.247262.

[41] Kandpal, T.C. and Broman, L., 2015. Renewable energy education: a worldwide status review. Stromstad Academy, 1-75.

[42] Khambalkar, V.P., Katkhede, S.S., Dahatonde, S., Korpe, N.D. and Nage, S.M., 2010. Renewable energy: an assessment of public awareness. International Journal of Ambient Energy, 31(3), pp.133-142.

[43] Tarsheed website, http://tarsheed.com/, accessed on 22 May 2018.

[44] The Qatar General Electricity \& Water Corporation (Kahrammaa), http://www.km.com.qa/Tarsheed/Pages/default.aspx\#front, accessed on 22 May 2018

[45] The Qatar General Electricity \& Water Corporation (Kahrammaa)http://www.km.com.qa/Tarsheed/Children/Pages/default.aspx , accessed on 22 May 2018

[46] The Qatar General Electricity \& Water Corporation (Kahrammaa), http://www.km.com.qa/Pages/default.aspx , accessed on 22 May 2018. 